\title{
Alvorecer do Paradigma Sistêmico na Educação Médica
}

\section{Dawn of the Systemic Paradigm in Medical Education}

\author{
Raquel Rangel Cesario ${ }^{1 \odot}$ \\ Manuel Cesario \\ Cibele Gomes dos Santos ${ }^{I}$
}

\section{PALAVRAS-CHAVE \\ - Conhecimento \\ - Pensamento Sistêmico. \\ - Paradigma. \\ - Ciência Novo- paradigmática. \\ - Educação Médica.}

A formação de médicos no Brasil seguia os moldes do projeto flexneriano até que o emergente Sistema Único de Saúde, com o diagnóstico da situação do setor saúde e a implantação de políticas de reorientação do modelo assistencial para um voltado à Atenção Básica, mostrou a necessidade de realinhar a formação médica às suas necessidades. As novas escolas médicas têm que iniciar com um modelo pedagógico que se utilize de metodologias ativas de ensino-aprendizagem, e as antigas escolas têm que se adaptar ao modelo proposto. Este momento de transição vem gerando conflitos, dificuldades, angústias, currículo oculto e incompreensões. Tal situação é decorrente da exigência de ultrapassagem de paradigmas para atuar no novo modelo pedagógico, sem, contudo, que as pessoas envolvidas tenham consciência disso. Vemos e interpretamos o mundo por meio dos nossos paradigmas, que agem como lentes que filtram o que enxergamos, estabelecem limites do que acreditamos, e influenciam nossas percepções e ações. Assim, o objetivo deste artigo é propor um olhar sobre conceitos e práticas neste momento de transição paradigmática, visando colaborar com a discussão e, principalmente, compreensão das incoerências, dificuldades e insucessos na implantação de projetos contemporâneos na área da saúde. O estudo das partes simples não é suficiente para entender o todo complexo, que deve ser estudado e compreendido em sua inteireza, a partir, inclusive, da sua relação com o outro. A instabilidade e a complexidade do mundo colocam em evidência a importância dos processos, do contexto de cada situação e das conexões sistêmicas entre todos os fenômenos. No emergente Pensamento Complexo, não cabem mais as contribuições isoladas de cada disciplina, mas exige-se o olhar e posicionamento interdisciplinar para buscar verdades construídas em conjunto, estabelecidas no contexto e na relação com o outro. Não se fala mais em saúde ou em doença, mas sim no processo saúde-doença; da mesma forma, o ensino e o aprendizado dão lugar ao processo de ensino-aprendizagem. Como característico em uma situação de transição paradigmática, há conflitos e diferenças de compreensão do mundo, que geram situações identificadas como crises. Vivemos sob a égide de dois paradigmas diferentes e simultâneos, que partilham conhecimentos e práticas: o Paradigma Newton-Cartesiano e o Paradigma Sistêmico. A partir da reflexão gerada por este artigo, espera-se que o leitor identifique o paradigma dominante em sua vida e seu posicionamento no contexto da transição paradigmática, compreenda os conflitos que enfrenta no seu trabalho e na sua vida, e se permita uma reorientação de rota, com vistas a viver melhor e atuar de forma mais coerente e saudável no mundo. 


\section{KEY-WORDS}

- Knowledge.

- Systemic Thinking.

- Paradigm.

- New-paradigmatic science.

- Medical Education.

Recebido em 9/6/19

Aceito em 3/8/19

\section{INTRODUÇÃO}

A Lei de Diretrizes e Bases da Educação ${ }^{1}$ brasileira recomenda uma educação que gere autonomia nos educandos. Entretanto, não é isso que se verifica nas escolas brasileiras, nas quais a educação continua sendo "bancária", nos moldes que Paulo Freire $^{2}$ já denunciou há mais de 40 anos. A educação médica tem trilhado um caminho diferente nas duas últimas décadas. A formação de médicos no Brasil seguia os moldes do projeto flexneriano até o advento do Sistema Único de Saúde (SUS). Esse, ao promover o diagnóstico da situação do setor saúde e a implantação de políticas de inversão do modelo assistencial focado nas especialidades médicas para um modelo que privilegia a atenção básica, gerou projetos como o PET-Saúde, que
ABSTRACT

The training of doctors in Brazil followed the Flexnerian project until the Unified Health System (SUS), with the diagnosis of the health sector situation and the implementation of policies to reorient the care model to one that favours Basic Care, showed the need to realign medical education to the needs of the emerging SUS. The new medical schools have to start with a pedagogical model that uses active teaching-learning methodologies, and the old ones have to adapt to this proposed model. This moment of transition is generating conflicts, difficulties, anxiety, hidden curriculum and misunderstandings. This situation is due to the need to overcome paradigms to act in the new pedagogical model, without, however, the people involved being aware of this. As we see and interpret the world through our paradigms, which act as lenses that filter what we see, establish limits of what is possible to believe and influence our perceptions and actions, the objective of this article is to propose a look at concepts and practices in this complex paradigmatic transition moment, aiming to collaborate with the discussion and, mainly, to understand the inconsistencies, difficulties and failures in the implementation of contemporary projects in the health education area. The study of the simple parts is not enough to understand the complex whole, which must be studied and understood in its entirety, from its relation to the other. The instability and complexity of the world highlight the importance of the processes, of the context of each situation, and the systemic connections between all phenomena. In the emerging Complex Thinking, the isolated contributions of each discipline no longer fit, but an interdisciplinary look and positioning is required to seek co-constructed truths, which are established in the context, and in the relationship with the other. One does not talk about health or disease anymore, but about the health-disease process; similarly, teaching and learning give way to the teaching-learning process. As characteristic in a paradigm transition situation, there are conflicts and differences regarding the understanding of the world, generating situations identified as crises. We live under the aegis of two different and simultaneous paradigms that share knowledge and practices: the Newton-Cartesian Paradigm and the Systemic Paradigm. From the reflection generated by this article it is expected that the reader will identify the dominant paradigm in their life and their consequent positioning in the context of the paradigmatic transition; will understand the conflicts faced in daily work and life; and will allow a route reorientation, aiming at living better and acting in a more coherent and healthy way in the world. 
Este momento de transição vem gerando conflitos, dificuldades, angústias, currículo oculto e incompreensões ${ }^{7,8,9}$. A nosso ver, tal situação é decorrente da necessidade de se superar paradigmas para a vigência do novo modelo pedagógico, sem, contudo, que as pessoas envolvidas tenham consciência disso.

A expressão "quebra de paradigmas" é recorrente nas capacitações docentes. Porém, a palavra "paradigma" pode ter significados diversos ${ }^{10}$ e portanto, é importante esclarecer qual o sentido de paradigma neste texto. Enquanto a expressão é correntemente utilizada como sinônimo de teoria, indicando regras e padrões de prática, queremos propor o significado que se refere a crenças e valores subjacentes à prática científica e à própria vida. Segundo Morin ${ }^{10}$, "os paradigmas são princípios supralógicos de organização do pensamento", ou seja, nós vemos e interpretamos o mundo por meio dos nossos paradigmas, que agem como lentes que filtram o que enxergamos, estabelecem limites do que é possível acreditar e influenciam nossas percepções e ações. "Quebrar" um paradigma, ou ultrapassá-lo, demanda perguntar-se "o que hoje me parece impossível fazer, mas, se fosse feito, mudaria radicalmente as coisas?"

No mundo ocidental contemporâneo, o paradigma ainda hegemônico foi conformado pelos pressupostos epistemológicos da ciência tradicional do século XVII ao XX. Epistemologia entendida aqui como as premissas implícitas que configuram a visão de mundo que todos têm ${ }^{10}$. A partir do século XX, novos pressupostos epistemológicos fizeram emergir o Paradigma Sistêmico, que coexiste com o tradicional. Essa coexistência, nem sempre harmônica, influencia e aumenta a complexidade das nossas práticas, tanto no campo da educação quanto no campo da medicina.

Assim, o objetivo deste artigo é propor um olhar sobre conceitos e práticas neste complexo momento de transição paradigmática, visando colaborar com a discussão e, principalmente, compreensão das incoerências, dificuldades e insucessos na implantação de projetos contemporâneos na área da saúde. A representação esquemática proposta pode ser utilizada para o entendimento de outros fenômenos no setor da saúde, mas neste artigo, o recorte principal será dado à educação médica, submetida às DCNs brasileiras de $2014^{6}$.

Para alcançar o intento, realizou-se um ensaio teórico a partir do livro "Pensamento Sistêmico: o novo paradigma da Ciência"10.

\section{A ciência tradicional e o mundo em que nascemos}

A história do mundo é dividida em Idades ou Períodos. Grandes acontecimentos marcam o fim de um Período e início de outro. Embora didaticamente escolha-se um evento ou uma data para marcar tal mudança, a transição se dá num processo que envolve anos ou décadas. Essa transição é, portanto, marcada pela intensidade de conflitos entre gerações de pessoas que convivem com visões de mundo diferentes, umas olhando e buscando o passado e a segurança do conhecido, e outras buscando criar novas perspectivas, com o foco no futuro.

Neste processo de transição de mundo, pode-se ressaltar três grandes momentos que revolucionaram a forma de pensar do Homem ${ }^{11}$. O primeiro foi a invenção da escrita, há cerca de 6000 anos. O segundo, a invenção da prensa, que permitiu a reprodução de manuscritos e promoveu a efervescência humana e cultural que caracterizou a passagem da Idade Média para a Idade Moderna, ampliando o universo dos homens e mulheres de então e, com isso, concedendo-lhes a oportunidade de ver e pensar o mundo através de outra lente. A terceira, a revolução digital, que vem mudando a forma como as pessoas se comunicam, se relacionam, e compreendem o mundo ${ }^{11}$. Esses eventos revolucionários levaram às chamadas "Transições Paradigmáticas".

Foi no segundo momento, entre os séculos XVI e XVII, que começou a se configurar a Ciência tal qual a conhecemos e praticamos hoje. A Transição Paradigmática que aconteceu na passagem da Idade Medieval para a Idade Moderna foi possível graças à presença inquieta, persistente e corajosa de filósofos, astrônomos, matemáticos e físicos como Nicolau Copérnico, Galileu Galilei, Francis Bacon, René Descartes, John Locke, Isaac Newton e outros. Esses homens resgataram da Antiguidade a descoberta do logos ao perceber que a verdade deveria ser encontrada por meio da razão, e não por revelação divina, como era hegemônico pensar nos 1000 anos precedentes. Decidiram que a razão deveria se utilizar de um método para ter certeza de que encontrariam a verdade. Cada um deles deu contribuições brilhantes e importantes, resgatando da Antiguidade a dúvida e o questionamento constante.

Francis Bacon, filósofo, político e cientista inglês, é considerado o fundador da Ciência Moderna. Ao publicar Novum Organum, em 1620, defendeu a necessidade de método e rigor para fugir dos equívocos provocados pela mente. Para Bacon, o único caminho para se alcançar o conhecimento verdadeiro é a utilização do empirismo indutivo, associado à neutralidade do cientista em relação ao objeto estudado.

Poucos anos mais tarde, na Europa continental, Descartes, também conhecido pelo seu nome latino Cartesius, defendeu o racionalismo por meio do método dedutivo. Em sua obra Discurso sobre o Método, publicada em 1637, encontra-se sua contribuição mais conhecida e utilizada na ciência atual, a máxima de fragmentar os objetos e fenômenos pesquisados até sua parte mais simples, acreditando que, ao conhecer exausti- 
va e analiticamente cada parte de um todo, o processo de síntese posterior, ou seja, a reunião do conhecimento das partes simples, permitiria o conhecimento verdadeiro do todo. Nasce assim, em meados do século XVII, por meio do método cartesiano, a simplicidade, que até hoje caracteriza a ciência tradicional ocidental. Outras importantes contribuições cartesianas foram a matematização da ciência e a inclusão da dualidade nos processos de análise. Começa aqui a separação entre logos e razão, filosofia e ciência, mente e corpo ${ }^{10,12}$. A análise das coisas e fenômenos leva o cientista a classificá-las em categorias excludentes: se um fenômeno faz parte da categoria $\mathrm{A}$, ele não pode pertencer, simultaneamente, à categoria B, ou C. A atitude ou-ou, tão presente na ciência tradicional e nas mentes humanas ainda hoje, nasce da compreensão cartesiana de mundo ${ }^{10}$.

Cinco décadas depois, o cientista inglês Isaac Newton introduziria a física como um dos pilares estruturantes da ciência, estabelecendo leis universais e comprovando a estabilidade dos sistemas e de todas as coisas. Considerado o pai da ciência natural, sua publicação Princípios Matemáticos da Filosofia Natural, de 1687, estabelece a Mecânica clássica e introduz a visão mecanicista do universo, seguida da visão do homem como máquina ${ }^{10,12}$.

Muitos outros filósofos e cientistas foram importantes nesse período, uns corroborando e outros discordando e avançando as proposições feitas no passado ${ }^{12}$. Mas esses três cientistas contribuíram de forma muito marcante com os pressupostos básicos da Ciência Tradicional, além do Paradigma Newton-Cartesiano, criado a partir de então, conformando a forma de pensar e enxergar o mundo da população ocidental, durante cerca de 300 anos seguintes. Para fins de compreensão da evolução do mundo no século XX, cumpre acrescentar a contribuição de Auguste Comte, em fins do século XIX, com a introdução do Positivismo, que consiste em adotar os métodos físicos e matemáticos utilizados na ciência natural para o estudo da sociedade humana, determinando a neutralidade, objetividade, simplicidade e estabilidade como pressupostos fundamentais para o estudo das pessoas ${ }^{10,12}$.

Todo esse desenvolvimento da metodologia científica provocou resultados extraordinários, avançando o mundo de forma antes jamais imaginada. Propiciou, por exemplo, a Revolução Industrial, com novas formas de relacionamento entre pessoas e dessas com os bens de consumo e produção; causou a urbanização e a necessidade do mercado de consumo para utilização dos produtos fabricados em série; descobriu formas de diagnosticar e tratar doenças, bem como sanear o meio, aumentando a expectativa de vida da população, e permitindo o crescimento populacional. $\mathrm{O}$ desenvolvimento da Ciência
Tradicional, também chamada de Ciência Moderna, concedeu às pessoas a possibilidade de terem suas necessidades básicas satisfeitas e de ir além. O século XX presenciou cada vez mais cientistas fazendo ciência, descobrindo e criando coisas; mas, presenciou também a marginalização do filósofo e da arte de pensar a ciência. A atitude reflexiva não se enquadra nos pressupostos que sustentam a ciência, e qualquer conhecimento adquirido por meio da reflexão não tem valor de verdade ${ }^{10}$.

\section{A Medicina e a Educação Médica na Ciência Tradicional}

$\mathrm{Na}$ área médica, a ciência moderna produziu grandes avanços. A explicação da causa das doenças evoluiu da mitologia para os Ares, Águas e Lugares, de Hipócrates. Na Idade Média, a vontade divina passou a ser a determinação única para explicar os males que se abatiam sobre o homem, a partir do seu comportamento condizente, ou não, com os preceitos da Igreja. Durante a Idade Moderna, a explicação vinha dos miasmas, o ar contaminado com partículas mortíferas que passaram a influenciar a arquitetura e o modo de vida das pessoas, com vistas a evitar sua contaminação. É precisamente neste momento histórico que nasce a Ciência, que vai permitir ao homem, a partir do séculos XVI e XVII, realizar necrópsias e correlacionar quadros clínicos com achados anatômicos, e inventar o microscópio, descobrindo e divulgando a existência de seres vivos invisíveis a olho nu e, mais tarde, a célula. Esses foram marcos de um momento importante na história da Biologia e da Medicina, com a Teoria Celular e o saber anátomo-patológico. Tal situação vai em progressão constante até que, em finais de século XIX, a Teoria Microbiana estabelece que a maior parte das doenças é causada por microrganismos, impulsionando a fabricação de vacinas e medicamentos para combater tais doenças, bem como ações de saneamento das cidades como forma de prevenção do contato com tais microrganismos $^{13,14}$.

A forma de ensinar medicina é revolucionada nos Estados Unidos a partir de 1910, quando o Relatório Flexner, baseado nas características de fragmentação disciplinar conferida pela Ciência e nas Teorias Celular e Microbiana - que estabeleciam a primazia da Biologia sobre o padecimento dos corpos - impõe um Ensino Médico especializado e fragmentado, dentro de estabelecimentos hospitalares segmentados por especialidades clínicas ${ }^{4,13}$.

Simultaneamente, com o crescente capitalismo e desenvolvimento da indústria, e as ideias positivistas de ordem e de progresso estabelecidas em prol do capitalismo, a forma de ensinar consistia na reunião disciplinar e disciplinada de pessoas em uma mesma sala, aprendendo a partir da experiência e autoridade do professor ${ }^{15}$. 
As ideias flexnerianas para Educação Médica tiveram sucesso nos Estados Unidos e proliferaram para outros países, como o Brasil, onde, a partir da década de 30, passou a influenciar a formação e atuação dos médicos. No pós-guerra, a invenção de equipamentos e medicamentos cada vez mais específicos para cada doença contribuiu para fortalecer a especialização e segmentação da Clínica Médica em sistemas orgânicos, distanciando o médico do paciente-pessoa, uma vez que o olhar profissional é direcionado exclusivamente para as alterações anátomo-patológicas do órgão doente do corpo físico e biológico de um homem, que precisa ser considerado como máquina para revelar as verdades do seu funcionamento fisiológico ou patológico ${ }^{13,14}$.

Tais métodos de ensinar e fazer medicina tiveram resultados extraordinários na compreensão de diversas doenças e no aumento da expectativa de vida das pessoas. Propiciaram a Transição Demográfica e Epidemiológica que se verificou no mundo durante o século XX, variando temporalmente de acordo com o nível de organização econômica e cultural de cada sociedade. Entretanto, deixaram de captar meandros da condição humana que culminaram com o surgimento de novas doenças, mentais e sociais, que estão em expansão no século $\mathrm{XXI}^{16}$, como por exemplo a depressão, os suicídios e outras formas de violência.

\section{Surge um outro paradigma}

A Ciência no século XX avançou a tal ponto que, em meados daquele século, equipamentos de laboratório com capacidade de ver o mundo em seus componentes atômicos e subatômicos permitiram a físicos e matemáticos observar a existência de fenômenos vibracionais que não se enquadravam nos pressupostos epistemológicos que sustentavam a Ciência Tradicional, como por exemplo, a estabilidade do mundo. Além dos físicos e matemáticos, sociólogos começaram a perceber que o estudo das partes simples não era suficiente para entender o todo complexo, e que esse deveria ser estudado e compreendido em sua inteireza, a partir, inclusive, da sua relação com o outro. A instabilidade e a complexidade do mundo colocam em evidência a importância dos processos, do devir, do contexto de cada situação e das conexões sistêmicas entre todos os fenômenos ${ }^{10}$.

Nasce assim o Pensamento Complexo, e começa a crescer no mundo o grupo de cientistas que advoga uma nova forma de fazer Ciência. Neste contexto não cabem mais as contribuições isoladas de cada disciplina, mas exige-se o olhar e posicionamento interdisciplinar para buscar verdades que se estabelecem no contexto e na relação com o outro. É precisamente a relação com o outro que agrega ao Pensamento Complexo, transmutando-o para o Pensamento Sistêmico ${ }^{10}$. Não se fala mais em saúde ou em doença, mas sim no processo saúde-doença; da mesma forma, o ensino e o aprendizado dão lugar ao processo de ensino-aprendizagem.

No fim do século XX surge no mundo a Revolução Digital, que representa a terceira grande mudança na forma de pensar da Humanidade, e na maneira como o homem se relaciona com as coisas e com outras pessoas. A partir daqui, nada será como antes. A Revolução Digital dá ao homem novas lentes através das quais passa a enxergar o mundo. E, por todo o exposto até aqui, este momento da história representa uma nova transição paradigmática. Presenciamos o desabrochar de uma nova Idade histórica; afinal, não faz mais sentido tratar o tempo atual no mesmo período histórico que a Queda da Bastilha, em 1789.

Esteves de Vasconcellos ${ }^{10}$ mostra a evolução dos pressupostos da Ciência Tradicional para a Ciência "Novo-Paradigmática": da estabilidade, evolui-se para a instabilidade; da simplicidade, à complexidade; da objetividade, à intersubjetividade.

Na transição entre os séculos XX e XXI, o conhecimento no mundo é tão extenso, especializado, segmentado, volúvel e exponencial, que a forma de lidar com ele exige mudanças profundas nas organizações sociais, como as de educação e de saúde. No mundo das organizações sociais, as relações passam a exigir um deslocamento da administração centralizada, controladora e hierarquizada, para relações de poder mais equânimes, com relacionamento e administração em redes, concedendo autonomia e responsabilidade a todos os membros da equipe, cultivando processos de liderança mais situacionais e menos autocráticos ${ }^{17,18}$.

Na Medicina, a crise no relacionamento entre médicos e pacientes se aprofunda, manifestada por crescente hostilidade desses à categoria profissional, que muitas vezes não consegue se enquadrar no sistema de saúde e de sociedade vigentes. Esta categoria profissional é a que apresenta maiores índices de suicídio e de sofrimento mental ${ }^{19}$.

$\mathrm{Na}$ área assistencial do setor Saúde, a dicotomia entre a atenção individual, especializada, curativa e "medicalizada", e a atenção coletiva, preventiva e pouco "medicalizada", evolui para a dicotomia entre a Atenção Básica e a Atenção Especializada. Ainda incapaz de conter a insustentabilidade desse modelo de atenção, a política pública clama pela necessidade de superação da dicotomia e, no Brasil, busca fazer isso pela via da formação de profissionais de saúde, de médicos em particular, que estejam alinhados aos pressupostos epistemológicos do paradigma emergente.

Na Educação, são cada vez mais aceitos métodos que colocam o sujeito aprendiz como protagonista do seu aprendi- 
zado, sempre mediado pelo seu conhecimento prévio e pela intersubjetividade das relações que estabelece com o meio e com os pares. Muda o papel do educador, que não necessita ser detentor de conhecimentos especializados sobre o que "ensina", e deixa de ter relação vertical de autoridade com seus alunos, e foca mais no desenvolvimento de competências, processos e atitudes que permitirão ao estudante buscar e relacionar-se de maneira apropriada com o conteúdo necessário ao desenvolvimento de suas atribuições estudantis e laborais futuras $3^{3,4,7,9,20}$. O paradigma emergente exige uma educação "libertadora", baseada na problematização e na inteligência, em vez da obediência² ${ }^{2}$.

Na Educação Médica, em particular, surgem novas metodologias de ensino-aprendizagem na década de 1970, centradas em processos ativos de aprendizagem pelos estudantes, com relações mediadas por professores-facilitadores. No Brasil, essas tecnologias chegaram devagar no fim dos anos 1990, foram estimuladas pela política pública no início dos anos 2000 e, a partir de 2014, recomendadas como práticas adequadas para a formação de profissional médico com o perfil condizente e necessário à política de saúde em vigor no país. A prática mais comum no Brasil é a Aprendizagem Baseada em Problemas (Problem-Based Learning - PBL), originária das Universidades McMaster, no Canadá, e Maastrich, na Holanda 6,21,22.

Contudo, como característico em uma situação de transição paradigmática, há conflitos e diferenças de compreensão do mundo, que geram situações identificadas como crises. Nos ambientes de trabalho ou de estudo, dirigentes, trabalhadores de diferentes níveis, docentes e discentes, não se entendem. Num país como o Brasil, onde a Filosofia está sendo relegada ao ostracismo, análises situacionais são feitas desconsiderando a transição paradigmática e sua influência sobre o desalinhamento dos processos e da implantação de projetos.

\section{Simultaneidade}

No tempo histórico atual vivemos sob a égide de dois paradigmas diferentes e simultâneos, que partilham conhecimentos e práticas que se alinham, ideologicamente, ao Paradigma Newton-Cartesiano, iniciado no século XVII e que caminha para seu fim; ou ao Paradigma Sistêmico, iniciado em fins do século XX (Figura 1).

Pode soar estranho ao leitor o ato de classificarmos conceitos e práticas sob dois paradigmas distintos, visto que a dualidade e a classificação são atos característicos da atitude ou-ou da Ciência Tradicional. A nosso favor cumpre observar, entretanto, que, para além do expediente didático para nos fazer entender pelo leitor, o Paradigma Sistêmico, seus conceitos e práticas, não negam o paradigma anterior, tampouco o "que-

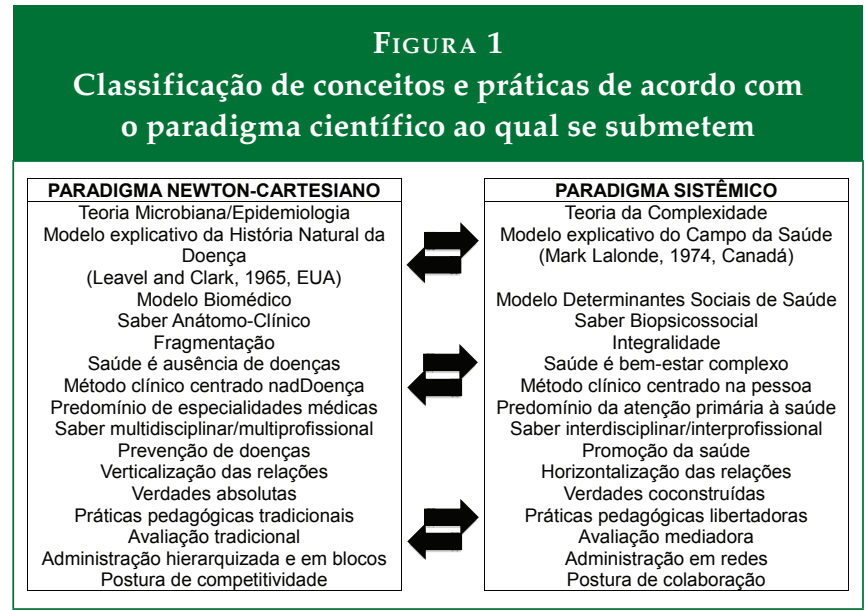

bram". São, antes, um desdobramento dele, ultrapassando-o de forma articuladora. Assim, o Saber Biopsicossocial (representando aqui a integralidade), por exemplo, inclui o Saber Anátomo-Clínico em seu radical "bio", e o método clínico centrado na pessoa inclui a investigação da doença, característica do método clínico centrado na doença. A atenção primária necessita fortemente das especialidades médicas em caráter complementar e específico; os diferentes espaços de cuidado não prescindem da atenção hospitalar, mas a incluem quando necessário. Por outro lado, as verdades absolutas perdem espaço, e evoluem para a compreensão das verdades coconstruídas, culminando com a evolução das relações e dos processos educacionais e organizativos para formas processuais horizontalizadas e em rede.

Os conceitos e práticas apresentados na Figura 1 são compreendidos e empreendidos por pessoas que atuam no mundo a partir de pressupostos epistemológicos que se enquadram no Paradigma Cartesiano ou no Sistêmico.

Se o leitor for um médico que se orgulha do seu conhecimento específico, que preza as evidências epidemiológicas e biológicas da doença e acredita que sua relação com o paciente deva ser pautada pela autoridade, mas também se insere como professor em um curso de medicina cujo projeto político-pedagógico é baseado em metodologias ativas de aprendizagem centradas no estudante e no desenvolvimento de competências, ele encontrará dificuldade em aceitar o método pedagógico como bom, porque, mesmo que teoricamente o admire, não tem capacidade para mudar sua postura epistemológica em direção a uma prática que privilegie as verdades coconstruídas, as relações horizontais e o olhar integral sobre o processo saúde-doença.

A maioria dos estudantes provêm de um sistema cartesiano de ensino que privilegia memorização e competitividade. 
Os estudantes de Medicina, especialmente, são aqueles que tiveram mais êxito nas práticas de memorização e no funil competitivo do vestibular. Quando entram em contato com o método pedagógico preconizado pelas $\mathrm{DCNs}^{6}$, alguns se adaptam, desenvolvendo práticas prioritariamente sistêmicas, enquanto outros resistem às necessárias mudanças, acusando docentes, currículo e instituição de incompetentes. Se estudantes com pensamento prioritariamente sistêmico lidam em grupo com outros estudantes com pensamento cartesiano, suas relações de competitividade ou colaboração estarão sujeitas ao perfil do docente que acompanha o grupo. Um docente com estilo de liderança hierarquizado e autocrático tenderá a valorizar a competição entre os estudantes; um docente com estilo de liderança situacional poderá desenvolver a empatia e colaboração entre os membros do grupo.

Um corpo diretivo que seja centralizador, autocrático, hierarquizado propiciará ao curso de Medicina uma cultura organizacional com grande dificuldade de dialogar com os pressupostos mais fundamentais do PBL, mantendo formas tradicionais de admissão e administração de pessoal, arquitetura que privilegie o ensino tradicional. Consequentemente, reproduzirá, um currículo nefasto à saúde das equipes docente e discente e que, ainda, poderá passar a impressão de que o método PBL não é bom. Além disso, cursos com projeto político pedagógico e programações baseados no desenvolvimento de competências, com metodologias ativas de ensino-aprendizagem, que se proponham a ser inovadores a partir da integração entre unidades curriculares, aprendizagem centrada no estudante e desenvolvedores de autonomia, mas tenham em seus quadros docentes e dirigentes com postura epistemológica tradicional, tenderão a realizar avaliações pontuais, fragmentadas e centradas no professor. Isso pode levar à deterioração do processo formativo, ansiedade e conflitos entre discentes, docentes e dirigentes, favorecendo até a alarmante epidemia de suicídios.

Ainda, currículos escolares voltados à integralidade e predomínio da atenção primária, que se desenrolam em cenários de prática de sistemas municipais de saúde com cultura hierarquizada, hospitalocêntrica e biomédica, terão dificuldade em ser implementados de forma a favorecer a aprendizagem significativa.

Acreditamos que muitos dos profissionais da Educação Médica no Brasil encontram-se em uma zona de transição entre paradigmas, no caminho para a ultrapassagem, e este movimento é fundamental para a atuação profissional saudável e eficiente no século XXI. A armadilha que todos devemos evitar é a "paralisia de paradigma" ou "doença fatal de certeza", quando cristalizamos um paradigma, que se torna o único modo de ver e atuar no mundo ${ }^{10}$.

\section{A alvorada}

Atendendo ao intuito deste artigo de propor um olhar sobre conceitos e práticas no mundo em transição paradigmática, a Figura 2 "resgata e integra a ciência tradicional, porém tendo agora um novo olhar sobre ela"10.

Figura 2

Educação médica no Paradigma Sistêmico

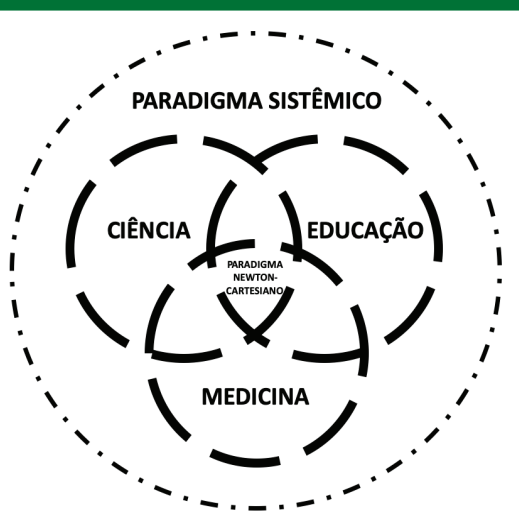

O que se propõe aqui é que, para compreender plenamente os conceitos e executar com excelência as práticas do Paradigma Sistêmico, exige-se que a pessoa tenha feito a ultrapassagem paradigmática e enxergue o mundo com a lente sistêmica. Por outro lado, no momento histórico atual, para compreender e atuar nos processos e práticas delimitados pelo Paradigma Newton-Cartesiano, essa exigência não é requerida. Entretanto, pessoas que tenham feito a ultrapassagem atuarão nesses lugares tendo uma nova postura epistemológica.

Por enquanto, no ano de 2019, quando se escreve este artigo, a formação em Medicina no Brasil enfrenta seu próprio processo de transição, recheado de conflitos e insatisfações, mas também alegrias e esperança. Com intenção de contribuir com as inquietações e diminuir angústias, o sujeito envolvido com educação Médica, seja ele estudante, docente, dirigente da Instituição de Ensino Superior ou trabalhador do sistema de saúde, poderá observar o que propusemos na Figura 2 e se perguntar onde e como ele se encaixa neste alvorecer.

O estudo da evolução histórica da ciência revela o estabelecimento dos padrões que governam a forma como a humanidade enxerga e se posiciona no mundo, mas a maior parte das pessoas vive sem ter consciência de como paradigmas determinam sua vida. $\mathrm{O}$ brevíssimo relato levado a cabo neste artigo apresenta ao leitor elementos da história que lhe permitam compreender o mundo atual e sua posição nele.

A partir da reflexão gerada por este artigo, espera-se que o leitor identifique o paradigma dominante em sua vida e 
seu posicionamento no contexto da transição paradigmática, compreenda os conflitos que enfrenta no seu trabalho e na sua vida, e se permita uma reorientação de rota, com vistas a viver melhor e atuar de forma mais coerente e saudável no mundo.

Finalmente, chegará o tempo em que a maioria das pessoas terá feito a transição e o paradigma hoje emergente será hegemônico, para depois ser substituído por outro.

\section{REFERÊNCIAS}

1. Brasil. Presidência da República. Lei nº . 9.394, de 20 de dezembro de 1996. Estabelece as Diretrizes e Bases da Educação Nacional. Diário Oficial da República Federativa do Brasil. Brasília DF, 23 de dezembro. Acesso em: 28 set. 2017. Disponível em: http://www.planalto.gov.br/ ccivil_03/Lei/QUADRO/1996.htm.

2. Freire P. Pedagogia da autonomia: saberes necessários à prática educativa. 7. ed. Rio de Janeiro: Paz e Terra, 1996.

3. Franco CAGS, Cubas MR, Franco RS. Currículo de Medicina e as Competências Propostas pelas Diretrizes Curriculares. Rev Bras Educ Med 2014;38(2)221-230.

4. Santos, CG. O ensino médico pelo prisma do estudante e o desenvolvimento da condição de agente: a perspectiva inovadora das metodologias ativas. Dissertação. Mestrado em Desenvolvimento Regional. Franca: Centro Universitário Municipal de Franca; 2019.

5. Brasil. Ministério da Educação. Conselho Nacional de Educação. Câmara de Educação Superior. Resolução CNE/ CES nº 04 de 07 de novembro de 2001. Institui diretrizes curriculares nacionais do curso de graduação em Medicina. Diário Oficial da União. Brasília, 9 nov. 2001;Seção 1, p.38.

6. Brasil. Ministério da Educação. Resolução n⿳ำ 03, de 20 de junho de 2014. Institui Diretrizes Curriculares Nacionais do Curso de Graduação em Medicina e dá outras providências. Diário Oficial da União, Brasília, 23 de junho de 2014 - Seção 1 - pag. 8-11.

7. Garcia MAA, Silva ALB. Um perfil do docente de Medicina e sua participação na reestruturação curricular. Rev. bras. educ. Med [online] 2011;35(1)58-68. Capturado em 07 ago. 2018. Disponível em: <http:/ /www.scielo.br/scielo. php?script=sci_arttext $\&$ pid $=$ S010055022011000100009\&ln $\mathrm{g}=\mathrm{en} \& \mathrm{nrm}=\mathrm{iso}>$.

8. Almeida EG, Batista NA. Desempenho docente no contexto PBL: essência para aprendizagem e formação médica. Rev. Bras. Ed. Médica 2013;37(2):192-201, 2013.

9. Peixoto MAP, Brandão MAG, Santos G. Metacognição e Tecnologia Educacional Simbólica. Rev. bras. educ. med. [online] 2007;31(1)67-80. Acesso em 22 ago. 2017. Disponí- vel em: <http://www.scielo.br/scielo.php?script=sci_artt ext\&pid=S010055022007000100010\&lng=pt\&nrm=iso $>$.

10. Esteves de Vasconcellos MJ. Pensamento Sistêmico: o novo paradigma da ciência. 10ª ed. Campinas: Papirus, 2013.

11. Nóvoa A. Pedagogia Universitária: já estamos no século XXI ou ainda não? Congresso Iberoamericano de Docência Universitária. Porto, 2012. Conferência de abertura. Univ. do Porto. Disponível em: <www.fpce.up.pt/ciie/cidu>. Acesso em 07 fev. 2018

12. Nielsen Neto H. Filosofia Básica. $3^{\text {a }}$ Ed. São Paulo:Atual, 1986.

13. Rodrigues RD, Anderson MIP. Integralidade e Complexidade na Medicina de Família e Comunidade e na Atenção Primária à Saúde: aspectos teóricos. In: Gusso G, Lopes JMC, Org. Tratado de medicina de família e comunidade: princípios, formação e prática. Porto Alegre: Artmed, 2012. p.60-70.

14. Batistella C. Saúde, doença e cuidado: complexidade teórica e necessidade histórica. In: Fonseca AF, Cobo AMD, Org. O Território e o processo saúde-doença. Rio de Janeiro: EPSJV /Fiocruz, 2007. p.25-49.

15. Leão DMM. Paradigmas Contemporâneos de Educação: escola tradicional e escola construtivista. Cadernos de Pesquisa 1999;107,187-206.

16. Prince M, Patel V, Saxena S, Maj M, Maselko J, Phillips MR, et al. No health without mental health. The Lancet 2007;370(9590)859-877.

17. Sisney L. Top-down vs. Bottom-up Hierarchy Or How to Design a Self-Managed Organization. In: Organizational Physics [Site na Internet]. Disponível em: https:/ / organizationalphysics.com/2016/10/13/top-down-vs-bottom-up-hierarchy-or-how-to-build-a-self-managed-organization/. Acesso em 04/05/2019.

18. Penha CD. Empresa-rede: talento nota 10. São Paulo: Cultura, 2012.

19. Santa ND, Cantilino A. Suicídio entre médicos e estudantes de medicina: revisão de literatura. Rev Bras Educ Med 2016;40(4)772-780.

20. Magalhães LKC, Azevedo LCSS. Formação continuada e suas implicações: entre a lei e o trabalho docente. Cad. Cedes 2015;35(95)15-36.

21. Berbel NAN. Problematização e a Aprendizagem Baseada em Problemas: diferentes termos ou diferentes caminhos? Interface - Comunic, Saúde, Educ 1998;2(2),139-154.

22. Tibério IFLC, Atta JA, Liechtenstein A. O aprendizado baseado em problemas - PBL. Rev Medicina [online] 2003;82(1-4)78-80. Acesso em 04 de maio de 2019. Disponível em http://www.revistas.usp.br/revistadc/article/ view/62624. 


\section{CONTRIBUIÇÃO DOS AUTORES}

Todos os autores tiveram participação equilibrada na concepção, redação e revisão do artigo.

\section{CONFLITO DE INTERESSES}

Nenhum dos autores apresenta conflito de interesses.

\section{ENDEREÇO PARA CORRESPONDÊNCIA}

Rua do Jatobá, 909 - Parque do Mirante - Franca - SP

14.410-354 - Brasil 